\title{
Long-term safety and efficacy of telmisartan/ amlodipine single pill combination in the treatment of hypertension
}

This article was published in the following Dove Press journal:

Vascular Health and Risk Management

15 March 2013

Number of times this article has been viewed

\section{Scott S Billecke \\ Pamela A Marcovitz}

Beaumont Health System, Ministrelli Women's Heart Center, Royal Oak, MI, USA
Correspondence: Scott S Billecke Ministrelli Women's Heart Center, Beaumont Health System, 360 I West Thirteen Mile Road, Royal Oak, MI 48073, USA

$\mathrm{Tel}+\mathrm{I} 2488987012$

Fax + I 2488983127

Email ssbillecke@gmail.com
Abstract: The use of multiple drug regimens is increasingly recognized as a tacit requirement for the management of hypertension, a necessity fueled in part by rising rates of metabolic syndrome and diabetes. By targeting complementary pathways, combinations of antihypertensive drugs can be applied to provide effective blood pressure control while minimizing side effects and reducing exposure to high doses of individual medications. In addition, combination therapies, including angiotensin converting enzyme (ACE) inhibitors and calcium channel blockers (CCBs), have the added benefit of reducing cardiovascular mortality and morbidity over other dual therapies while providing equivalent blood pressure control. It is possible that angiotensin receptor blockers (ARBs), which unlike ACE inhibitors are minimally affected by upregulation of alternative pathways for angiotensin II accumulation following long-term treatment, would also provide such outcome benefits. At issue, however, is maintaining patient compliance, as adding medications is known to reduce adherence to treatment regimens. The purpose of this review is to summarize existing trial data for the long-term safety and efficacy of a recent addition to the armamentarium of dual-antihypertensive therapeutic options, the telmisartan/amlodipine single pill combination. The areas where long-term data are lacking, notably clinical information regarding minorities and women, will also be discussed.

Keywords: Angiotensin receptor blocker, antihypertensive, calcium channel blocker, clinical trial, combination pill

Hypertension remains the most prevalent cardiovascular disease (CVD) risk factor and is present in ever-growing numbers worldwide. ${ }^{1,2}$ In the United States hypertension affects over $30 \%$ of adults or approximately 76,400,000 (2008 data) men and women age $\geq 20$ years. Data from the National Health and Nutrition Examination Survey indicate that approximately $8 \%$ of adults in the United States have undiagnosed hypertension, and of those diagnosed only three-quarters use antihypertensive medications. Among those taking medication, blood pressure (BP) is controlled in only half. ${ }^{3}$ The societal and financial burden of hypertension is not likely to reverse soon as projections suggest a $10 \%$ increase in hypertension prevalence by the year $2030 .{ }^{4}$ These statistics are especially troubling when one considers the consequences of hypertension; elevated BP $(>140 / 90 \mathrm{mmHg}$ ) precedes myocardial infarction (MI), stroke, or congestive heart failure in $\geq 69 \%$ of cases. ${ }^{5}$ Improved awareness and effective treatments, therefore, remain foremost goals for the patient and physician.

The cardiovascular risk associated with high $\mathrm{BP}$ and its prevalence is influenced by numerous factors, including race, gender, and underlying comorbidities. In the United States, black communities are characterized by a high incidence of hypertension, with African-American adults displaying an occurrence rate of $41.4 \%$ compared with $28.1 \%$ 
for whites; this disparity contributes to a 1.3- and 1.8-fold greater incidence of nonfatal and fatal stroke, respectively, and a 4.2-fold higher rate of end-stage kidney disease for blacks compared with whites. ${ }^{5}$ Hypertension is more common in men than women until age 64 , after which more women are hypertensive. ${ }^{5}$ Despite this, women have historically been underrepresented in antihypertensive drug trials, and it is notable that among the randomized controlled trials used to formulate the 2007 American Heart Association guideline update for CVD prevention in women, ${ }^{6}$ female participants represented only $31 \%$ of enrollees in, for example, the angiotensin converting enzyme (ACE) inhibitor/angiotensin II receptor blocker (ARB) trials. ${ }^{7}$ Furthermore, BP control rates are reduced up to $15 \%$ for women compared with men. ${ }^{8}$

Diabetics represent a population in which hypertension is especially difficult to control, often requiring $\geq 3$ antihypertensive medications to achieve the BP target of $<130 / 80 \mathrm{mmHg}$ recommended by the American Diabetes Association and the Seventh Joint National Committee of the National High Blood Pressure Education Program guidelines. ${ }^{9,10}$ This experience exemplifies the difficulties in achieving target BP in hypertensive patient groups. Numerous factors contribute to these challenges, including the ineffectiveness of monotherapy and poor medication compliance. Many hypertensive individuals fail to reach target BP with monotherapy, and current recommendations for individuals diagnosed with hypertension whose systolic BP (SBP) or diastolic BP (DBP) are $20 \mathrm{mmHg}$ or $10 \mathrm{mmHg}$ above target, respectively, are that they receive two antihypertensive medications that feature complementary mechanisms of action. ${ }^{1,11-13}$ Medication noncompliance, however, is the most common reason for failure to meet BP goals ${ }^{14-16}$ and is a consequence of the asymptomatic and chronic nature of the disease, tolerability issues, and physician-related factors. ${ }^{17}$ Increasing drug dose has been shown to reduce compliance by nearly $20 \%,{ }^{18}$ whereas reducing dose can increase adherence by essentially the same margin. ${ }^{19}$ The number of medications given correlates with discontinuation rate, an effect that may be minimized by the use of single pill combination drugs, which can improve compliance by as much as $25 \%{ }^{20-24}$

The use of single pill combination drugs has additional benefits beyond improved compliance. Blood pressure control is improved with antihypertensive combination pills compared with higher dose monotherapy, ${ }^{25}$ and the use of lower doses for two drugs minimizes side effects, provided that the side-effect profiles are dissimilar. ${ }^{26,27}$ Single pill combination therapy may provide cost savings through better BP control requiring fewer physician visits and hospitalizations for cardiovascular events. ${ }^{22,28,29}$ Furthermore, recent clinical trials have provided evidence for improved cardiovascular outcomes when taking certain antihypertensive drug combinations. Results from the Avoiding Cardiovascular Events in Combination Therapy in Patients Living with Systolic Hypertension trial showed significant, essentially equivalent BP improvement in those receiving either the ACE inhibitor benazepril and the calcium channel blocker (CCB) amlodipine or benazepril plus a diuretic (hydrochlorothiazide; HCTZ). ${ }^{30}$ However, the amlodipine arm also produced significant reductions in cardiovascular mortality and morbidity compared with the HCTZ arm, suggesting a non-hemodynamic vascular benefit associated with the ACE inhibitor/CCB combination, likely via effects on the renin-angiotensin system (RAS). Of note, because patients initiated on ARB therapy exhibit greater maintenance of treatment than for other antihypertensives, ${ }^{31-33}$ use of an ARB in place of an ACE in this combination may further improve compliance and, by extension, outcomes. While it is unclear whether ARB/amlodipine combinations provide similar outcome benefits, a 4-year prospective study is currently underway in China to explore the potential cardiovascular mortality and morbidity benefits of ARB + amlodipine treatment versus diuretic + amlodipine. ${ }^{34}$ Results from this study should provide additional insights regarding the effectiveness of these antihypertensive drug combinations in BP control and hard clinical endpoints.

One recent dual antihypertensive single pill combination with promising clinical impact is Twynsta ${ }^{\circledR}$ (Boehringer Ingelheim, Ingelheim, Germany), a telmisartan/amlodipine combination pill approved by the US Food and Drug Administration in 2009 and the European Medicines Agency the following year. Amlodipine (Norvasc ${ }^{\circledR}$; Pfizer Pharmaceuticals, New York, NY, USA), a CCB in the dihydropyridine class, has been used extensively since its approval in 1993, whereas telmisartan (Micardis ${ }^{\circledR}$, Boehringer Ingelheim, Ingelheim, Germany) has a shorter clinical history, having been approved in 2000. Each antihypertensive drug has been combined with multiple other antihypertensive medications into a single pill, but this combination is unique in that it combines the only ARB currently indicated for the prevention of CVD progression (telmisartan) with one of the most broadly used and well-studied CCBs (amlodipine). The clinical safety and efficacy of both telmisartan and amlodipine monotherapy for hypertension have been reviewed extensively elsewhere. ${ }^{35-38}$ The purpose of this review is to briefly describe the complementary mechanisms of action of telmisartan and amlodipine and detail the long-term safety and efficacy profile of the telmisartan/amlodipine combination pill. An emphasis will 
also be placed on populations underrepresented in these trials and the potential implications of this knowledge deficit.

\section{Pharmacokinetics and pharmacodynamics of telmisartan and amlodipine}

Telmisartan and amlodipine reduce BP through complementary mechanisms that are synergistic in their BP-lowering effects; their individual mechanisms of action have been extensively reviewed elsewhere. ${ }^{39-42}$ The telmisartan chemical structure possesses the biphenyl-tetrazol and imidazol groups common to all ARBs (Figure 1). Telmisartan is highly selective for the angiotensin II type 1 receptor (AT1) where it blocks the deleterious effects of ang II, which include vasoconstriction; activation of the protein kinase $\mathrm{C}$, NADPH oxidase, Janus kinase/signal transducer and activator of transcription cascade; release of catecholamines from the adrenal medulla; aldosterone secretion; and cell proliferation. ${ }^{43,44}$ In addition, at higher but still clinically relevant doses, telmisartan acts as a partial agonist of peroxisome proliferator-activated receptor $\gamma$ and as such produces beneficial effects in patients by improving glucose intolerance, insulin resistance, and lipid metabolism. ${ }^{45,46}$ Amlodipine, in contrast, is a dihydropyridine $\mathrm{CCB}$ that binds to a transmembrane site on L-type calcium channels within cardiac and smooth muscle cells, thereby inhibiting calcium ion influx with downstream disruption of myosin-actin interactions to reduce muscle contractility. ${ }^{36}$ The net effect of amlodipine on

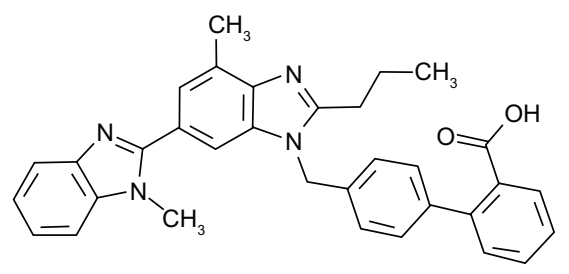

Telmisartan

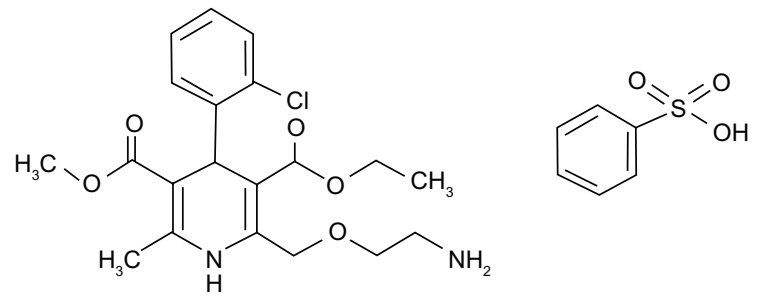

Amlodipine besylate

Figure I Chemical structures of telmisartan and amlodipine besylate. the vasculature is vasodilation resulting in lower peripheral resistance and a reduced $\mathrm{BP}$.

Individually, telmisartan and amlodipine exhibit different pharmacokinetic profiles with regard to rate of absorption, volume of distribution, and metabolism. Of the ARBs marketed for hypertension, telmisartan is the most lipophilic, a characteristic contributing to it having the longest half-life, highest AT1 receptor affinity, and largest volume of distribution among the ARBs. ${ }^{37,47,48}$ The bioavailability of telmisartan is approximately $45 \%$ to $50 \%$ and that of amlodipine is between $64 \%$ and $90 \%$. Amlodipine is extensively bound to plasma proteins (93\%) as is telmisartan (>99\%). Steady-state blood levels of amlodipine are achieved in 7 to 8 days ${ }^{49}$ and in 5 to 7 days for telmisartan. ${ }^{50}$

Both telmisartan and amlodipine have relatively long half-lives, from 20 to 30 hours for the former and 44 hours or more for the latter. ${ }^{51-53}$ Telmisartan does not undergo significant first-pass metabolism, and the majority (approximately $97 \%$ ) is eliminated by biliary-fecal excretion as the parent compound, although a small percentage of the drug undergoes glucuronidation. ${ }^{51}$ Amlodipine, in contrast, is converted to inactive metabolites hepatically with approximately $60 \%$ excreted as metabolized products and $10 \%$ as parent compound in urine. ${ }^{49}$ The effect of telmisartan and amlodipine coadministration on the other's pharmacokinetic profile is reportedly equivalent to the individually administered compounds, with the two-sided $90 \%$ confidence intervals for all pharmacokinetic endpoints residing within the standard bioequivalence acceptance interval ( $80 \%$ to $125 \%))^{54,55}$ Taking telmisartan/amlodipine with a high-fat meal can reduce telmisartan plasma concentrations by about $25 \%$ and increase amlodipine slightly compared with fasting conditions. ${ }^{56}$

A recently appreciated aspect of RAS inhibition is the presence of alternative pathways capable of producing ang II without any appreciable contribution by ACE. Most antihypertensive agents increase plasma renin activity leading to accumulation of ang I, which in turn helps facilitate metabolism of ang I into ang II via alternative pathways, most notably chymase activity in cardiac monocytes, vascular smooth muscle cells, and renal mesangial cells; this so-called "ACE escape" can result in a diminished response to drug over time. ${ }^{57-60}$ In addition, the phenomenon of aldosterone breakthrough has been reported for both ACE inhibitors and ARBs, representing another deleterious compensatory mechanism exposed by these medication classes. ${ }^{61,62}$

RAS inhibition may also have an unexpected effect on a novel counterregulatory and cardioprotective pathway involving the peptide angiotensin (1-7), a product of 
ang I or ang II cleavage produced by numerous enzymes, including prolyl-endopeptidase, prolyl-carboxypeptidase, neutral-endopeptidase, and ACE2. ${ }^{63-65}$ Angiotensin (1-7) is a vasodilator that targets the $\mathrm{G}$ protein-coupled Mas receptor both peripherally and centrally. ${ }^{66}$ Activated Mas receptors are thought to interact with ang II receptors as a physiologic antagonist and increase nitric oxide and prostaglandin release resulting in vasodilation, reduced fibrosis, diminished cardiac hypertrophy, and a decrease in cell proliferation. ${ }^{67}$ Both ACE inhibitors and ARBs have been shown to increase plasma ang (1-7), ${ }^{68,69}$ and a preclinical study showed that telmisartan can upregulate ACE2 and the ang (1-7) receptor in a dilated cardiomyopathy model, ${ }^{70}$ suggesting that the mechanisms yielding their clinical benefits may go beyond their effects on the traditional RAS pathway.

\section{Phase III clinical studies}

Although reports on the safety and efficacy of telmisartan/ amlodipine combination pill therapy are available from several short-term trials, in this review we focus on longterm studies, specifically those evaluating telmisartan/ amlodipine safety and efficacy over 6 months or more. Two such studies were extensions of prior trials entitled TElmisartan plus AMlodipine Study-Amlodipine $5 \mathrm{mg}$ and $10 \mathrm{mg}$ (TEAMSTA-5 and TEAMSTA-10) that collectively followed 1814 patients (40\% women) randomized to telmisartan $40 \mathrm{mg}$ /amlodipine $5 \mathrm{mg}$ (T40/A5), T80/A5 (TEAMSTA-5), T40/A10, or T80/A10 (TEAMSTA-10) with further delineations based on add-on therapy or uptitration to a higher telmisartan dose. ${ }^{71}$ A third long-term trial of 56 weeks duration with results posted on ClinicalTrials.gov (NCT00618774) and the manufacturer's web site enrolled 259 nonresponders to T40/A5 or A5 treatment (ie, SBP and DBP failed to reach $<140 \mathrm{mmHg}$ and $<90 \mathrm{mmHg}$, respectively, or decrease by $\geq 20 \mathrm{mmHg}$ and $\geq 10 \mathrm{mmHg}$, respectively) who were identified during the course of two prior studies (ClinicalTrials.gov identifiers NCT00558064 and NCT00550953). A fourth trial spanning 48 weeks was designed to assess the long-term safety of telmisartan/ amlodipine combination therapy in 210 hypertensive type 2 diabetics with microalbuminuria whose BP was not controlled (ie, $>130 / 80 \mathrm{mmHg}$ ) by T40/A2.5. ${ }^{72}$

Inclusion and exclusion criteria for the studies were similar with the exception being the study in microalbuminuric type 2 diabetics. This trial enrolled patients whose diabetes was well controlled by diet or oral medication but had two 24-hour urine collections test positive for microalbuminuria $(>30$ and $<300 \mathrm{mg} / 24$ hours). Of note, the upper dose of telmisartan used in this study, $160 \mathrm{mg}$, exceeds the maximum recommended dose for the drug and was selected to observe the effects of high-dose telmisartan/amlodipine on urinary albumin excretion. For the others, participants were typically men and women age $\geq 18$ years with essential hypertension who had either failed to respond to amlodipine $5 \mathrm{mg}$ (ClinicalTrials.gov identifiers NCT00558064 and NCT00614380) or telmisartan $40 \mathrm{mg}$ (NCT00550953). Some common exclusion criteria for the TEAMSTA trials included the following: taking four or more antihypertension medications; secondary hypertension; severe hypertension (SBP $\geq 200 \mathrm{mmHg}$ or $\mathrm{DBP} \geq 114 \mathrm{mmHg}$ ); pregnant or nursing women, or premenopausal women facing potential pregnancy; relevant cardiac arrhythmias; congestive heart failure (New York Heart Association class II-IV); recent MI, stroke, or transient ischemic attack; unstable angina; hyperkalemia or sodium deficiency; angioedema with ARB or ACE inhibitor treatment, or other hypersensitivity to study medications; hepatic and/or renal dysfunction; and chronic use of nonsteroidal anti-inflammatory drugs.

\section{Telmisartan/amlodipine safety}

Individually, amlodipine and telmisartan produce a generally low incidence of adverse events (AEs) and are well tolerated. The combination may be especially appropriate for those with diabetes and/or metabolic syndrome as these medications do not worsen the metabolic complications associated with their etiology. Most of the trials in which the safety of the telmisartan/amlodipine single pill combination was evaluated were of short duration. ${ }^{53}$ In an 8-week, placebo-controlled, $4 \times 4$ factorial design trial, safety was addressed in groups receiving T40/A5, T40/A10, T80/A5, T80/A10, T40, T80, $\mathrm{A} 5, \mathrm{~A} 10$, and placebo. AEs occurred within treatment groups at rates similar to those experienced by the placebo group, which had an overall $\mathrm{AE}$ incidence of $39 \%$ compared with a high of $44 \%$ in the T80/A10 group and a low of 33\% in the T40/A5 group. The AEs suspected to be drug related were as low as $5.2 \%$ (T80) and as high as 19\% (T80/A10). The most common AE was peripheral edema, a common side effect of amlodipine attributed to its vasodilatory capacity; ${ }^{42}$ the incidence of peripheral edema was as high as $18 \%$ in the A10 group and $11 \%$ in the T80/A10 group. The reduction in peripheral edema observed in the T80/A10 group compared with A10 monotherapy has been observed previously with this drug combination ${ }^{73,74}$ and with other RAS inhibitors, ${ }^{48,75,76}$ an effect that further validates choosing such combinations.

Safety information from the longer term trials described previously are shown in Tables 1 and 2 and reflect data from a total of 2283 patients. TEAMSTA study data include 
incidence of AEs per 100 patient years as the study designs called for uptitration in nonresponders; this same approach was taken for trial NCT00618774, but patient-year data were not available. Among the three trials with AE data delineated by treatment group (Table 1), overall all-cause AEs occurred at incidence rates as low as 12\% (T40/A10; TEAMSTA-10), with incidence rates per 100 patient years being $\leq 51$ occurrences. Interestingly, the overall incidence rate was $77 \%$ in both arms of the unpublished trial (NCT00618774); however, drug-related AEs did not exceed $8 \%$, or 14 incidences per 100 patient years, for any trial. Discontinuations due to AEs were low among all four studies, occurring at $<2 \%$. As with the short-term trials, the most common AE was peripheral edema, with increasing incidence among those receiving higher amlodipine doses; a few incidences of dizziness were also reported, and no deaths occurred during the trials.

Of the four long-term trials, only the albuminuria study presented clinical laboratory data (Table 2). Serum potassium levels appeared stable among arms, increasing slightly in those receiving T160/A2.5 but to a lesser extent than has been reported for ACE inhibitors alone or in combination. ${ }^{77}$

\section{Telmisartan/amlodipine efficacy}

Efficacy results from three long-term studies are compiled in Table 3. The majority of telmisartan/amlodipine trials utilized DBP control rate (ie, $<90 \mathrm{mmHg}$ ) as the primary efficacy outcome. This target was reached in $\geq 76 \%$ of participants that did not require maximal uptitration and add-on therapy (T80/A5 + drug, TEAMSTA-5) or uptitration (T80/A5, trial
1235.16); in these groups, DBP was controlled in $46.4 \%$ and $66.7 \%$ of recipients, respectively. DBP response rates, defined as DBP $<90 \mathrm{mmHg}$ or decreased by $\geq 10 \mathrm{mmHg}$, were no lower than approximately $69 \%$, and SBP response rates (SBP $<140 \mathrm{mmHg}$ or decreased by $\geq 15 \mathrm{mmHg}$ ) were $>70 \%$ in all groups. Mean BP reductions (Figure 2) indicated significant reductions in all arms, with each improvement $\geq 12.6 / 9.5 \mathrm{mmHg}$. Changes in BP did not typically follow a general dose-response trend within each study; this likely reflected their study designs, which often involved increasing dose or adding therapy in nonresponders as opposed to straight randomization.

None of these long-term studies were designed to compare telmisartan/amlodipine with monotherapy using these or other antihypertensive medications; such trials have generally been limited to 8 -week durations. ${ }^{73,78-81}$ Trials comparing telmisartan/amlodipine with other single pill combinations are likewise few; however, Bekki et al recently described the effect of T80/A5 combination therapy on the BP of 47 patients nonresponsive to amlodipine $5 \mathrm{mg}$ plus valsartan $80 \mathrm{mg}$ or candesartan $8 \mathrm{mg} .{ }^{82}$ In this study, participants experienced significant decreases in BP, from a baseline of $144 / 82$ to $135 / 78 \mathrm{mmHg}$ at 12 weeks $(P<0.001)$. As this was not a randomized controlled study, it is difficult to compare the efficacies of ARB/amlodipine combinations. However, head-to-head trials of ARB monotherapy have suggested that telmisartan provides greater BP control throughout the day, a likely outcome of its long half-life compared with other ARBs. ${ }^{83-85}$

Table I Safety profile for telmisartan/amlodipine combination therapy: adverse event reporting

\begin{tabular}{|c|c|c|c|c|c|c|}
\hline & \multicolumn{2}{|l|}{ TEAMSTA-5 } & \multicolumn{2}{|l|}{ TEAMSTA-I0 } & \multicolumn{2}{|c|}{ Trial no I 235.16} \\
\hline & $\begin{array}{l}\text { T40/A5 } \\
n=976 \\
n(\%)\end{array}$ & $\begin{array}{l}\text { T80/A5 } \\
\mathrm{n}=397 \\
\mathrm{n}(\%)\end{array}$ & $\begin{array}{l}\text { T40/A I0 } \\
n=838 \\
n(\%)\end{array}$ & $\begin{array}{l}\text { T80/AI0 } \\
n=6 I I \\
n(\%)\end{array}$ & $\begin{array}{l}\text { T40/A5 } \\
n=2 \text { I I } \\
n(\%)\end{array}$ & $\begin{array}{l}\text { T80/A5 } \\
n=48 \\
n(\%)\end{array}$ \\
\hline \multirow[t]{2}{*}{ All-cause AEs } & $381(39)$ & $201(5 I)$ & $102(12)$ & $157(26)$ & $163(77)$ & $37(77)$ \\
\hline & 95 per 100 PY & 97 per 100 PY & 50 per 100 PY & 46 per $100 \mathrm{PY}$ & & \\
\hline \multirow[t]{2}{*}{ Discontinuations due to AEs } & $12(1.2)$ & $4(1.0)$ & $6(0.7)$ & $9(1.5)$ & - & - \\
\hline & 3 per 100 PY & 2 per $100 \mathrm{PY}$ & 3 per 100 PY & 3 per 100 PY & & \\
\hline \multirow[t]{2}{*}{ SAE } & $22(2.3)$ & $6(1.5)$ & $4(0.5)$ & $13(2.1)$ & $9(4.3)^{\mathrm{a}}$ & $3(6.3)^{\mathrm{a}}$ \\
\hline & 4 per 100 PY & 4 per 100 PY & 3 per 100 PY & 2 per $100 \mathrm{PY}$ & & \\
\hline \multirow[t]{2}{*}{ Study-drug related $\mathrm{AE}$} & $5 I(5.2)$ & $30(7.6)$ & $28(3.3)$ & $38(6.2)$ & $4(1.9)$ & $2(4.2)$ \\
\hline & 13 per 100 PY & 14 per 100 PY & 14 per I00 PY & II per I00 PY & & \\
\hline \multicolumn{7}{|c|}{ Treatment-related AE occurring in $>1 \%$ of patients in any treatment group } \\
\hline Peripheral & $23(2.4)$ & II (2.8) & $16(1.9)$ & $24(3.9)$ & - & - \\
\hline Edema & 6 per 100 PY & 5 per 100 PY & 8 per $100 \mathrm{PY}$ & 7 per 100 PY & & \\
\hline \multirow[t]{2}{*}{ Dizziness } & 0 & $6(1.5)$ & 0 & 0 & - & - \\
\hline & & 3 per 100 PY & & & & \\
\hline
\end{tabular}

Notes: Number of participants (n) represents the number analyzed for the primary efficacy endpoints with the exception of TEAMSTA-I0, which analyzed all participants

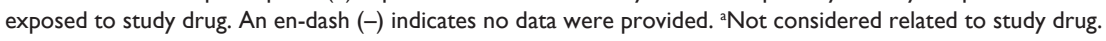

Abbreviations: T, telmisartan; A, amlodipine; TEAMSTA, TElmisartan plus AMlodipine Study-Amlodipine; AE, adverse event; PY, patient years; SAE, serious adverse event. 
Table 2 Laboratory and safety data from type 2 diabetics with microalbuminuria whose blood pressure was not controlled by telmisartan $40 \mathrm{mg} /$ amlodipine $2.5 \mathrm{mg}$

\begin{tabular}{|c|c|c|c|c|c|c|}
\hline & \multicolumn{3}{|c|}{ Increasing telmisartan dose group } & \multicolumn{3}{|c|}{ Increasing amlodipine dose group } \\
\hline & $\begin{array}{c}\text { T80/A2.5 } \\
n=35\end{array}$ & $\begin{array}{c}\text { TI20/A2.5 } \\
n=33\end{array}$ & $\begin{array}{c}\text { TI60/A2.5 } \\
n=34\end{array}$ & $\begin{array}{l}\text { T40/A5 } \\
n=43\end{array}$ & $\begin{array}{c}\text { T40/A7.5 } \\
n=32\end{array}$ & $\begin{array}{c}\text { T40/A } 10 \\
n=24\end{array}$ \\
\hline Creatinine clearance (mL/minute) & $92.9 \pm 8.5$ & $93.3 \pm 8.9$ & $91.5 \pm 7.9$ & $94.5 \pm 8.8$ & $93.9 \pm 8.7$ & $94.2 \pm 8.9$ \\
\hline Fasting blood glucose (mg/dL) & $126.4 \pm 19.3$ & $128.2 \pm 21.1$ & $125.4 \pm 18.3$ & $129.2 \pm 20.4$ & $131.8 \pm 21.7$ & $129.1 \pm 20.0$ \\
\hline $\mathrm{HbA}_{\mathrm{Ic}}(\%)$ & $6.7 \pm 1.2$ & $6.5 \pm 1.0$ & $6.6 \pm 1.1$ & $6.6 \pm 0.9$ & $6.9 \pm 1.1$ & $6.7 \pm 0.9$ \\
\hline Plasma K (mmol/L) & $4.1 \pm 0.5$ & $4.2 \pm 0.7$ & $4.3 \pm 0.8$ & $4.1 \pm 0.4$ & $4.0 \pm 0.4$ & $4.2 \pm 0.7$ \\
\hline $\begin{array}{l}\text { Urinary albumin excretion rate } \\
\text { (mg/24 hour) }\end{array}$ & $69.5 \pm 32.1$ & $45.9 \pm 25.9$ & $30.3 \pm 18.5^{a}$ & $89.3 \pm 40.3$ & $85.2 \pm 36.2$ & $90.5 \pm 42.1$ \\
\hline \multicolumn{7}{|l|}{ Adverse events, n (\%) } \\
\hline Total AEs & & $10(10)$ & & & $15(14)$ & \\
\hline Leg edema & & $0(0)$ & & & $7(7)$ & \\
\hline Dizziness & & $5(5)$ & & & $0(0)$ & \\
\hline Headache & & $I(I)$ & & & $3(3)$ & \\
\hline Hot flushes & & $0(0)$ & & & $3(3)$ & \\
\hline Nausea & & $3(3)$ & & & $0(0)$ & \\
\hline Asthenia & & $2(2)$ & & & $0(0)$ & \\
\hline Palpitations & & $0(0)$ & & & $2(2)$ & \\
\hline
\end{tabular}

Note: ${ }^{a} P<0.05$ vs telmisartan $80 \mathrm{mg}$.

Abbreviations: $T$, telmisartan; $A$, amlodipine; $A E$, adverse event; $H b A_{I c}$, hemoglobin $A_{I c}$.

Of concern with the data presented by the original and extended TEAMSTA studies is the very low representation of blacks; of the approximately 1800 participants in the long-term studies, only 16 were black. ${ }^{71}$ As hypertension is especially prevalent in black communities, with data from 2007-2010 showing African-American men and women having high rates of occurrence ( $40.5 \%$ and $44.3 \%$, respectively) and uncontrolled hypertension in those receiving treatment $\left(71.5 \%\right.$ and $51.0 \%$, respectively), ${ }^{86}$ the alarming lack of data in this population highlights the need for further shortand long-term studies to validate the efficacy and safety of T40/80-A5/10 single pill combination in black populations. In addition, as with many antihypertension studies, women were somewhat underrepresented in the study populations; of the 2078 participants in the four long-term studies noted here, 890 were women (43\%). Just as importantly, participants in the two published telmisartan/amlodipine pharmacokinetic studies described previously were all male and none were black or Hispanic ${ }^{54,55}$ (although the unpublished ClinicalTrials. gov study NCT01181011 did include ten women among the 28 participants). Telmisartan clearance is reduced in women, resulting in twofold to threefold higher plasma concentrations and a greater systolic BP response than is observed in men, ${ }^{53}$ and furthermore the pharmacokinetic profile of telmisartan alone or in combination with amlodipine in blacks or Hispanics has, to our knowledge, not been reported. In women, it is not

Table 3 Efficacy results from long-term ( $\geq 6$ months) telmisartan/amlodipine single pill clinical trials

\begin{tabular}{|c|c|c|c|c|c|c|}
\hline Study & Duration, week & Regimen $^{\mathrm{a}}$, mg/day & No & DBP controlb, \% & DBP responsec, \% & SBP response ${ }^{d}, \%$ \\
\hline Telmisartan plus & 34 & T40/A5 & 553 & 91.1 & 91.1 & 88.6 \\
\hline amlodipine study- & & T80/A5 & 206 & 77.7 & 83.0 & 86.9 \\
\hline amlodipine $5 \mathrm{mg}$ & & T40/A5+Add-on ${ }^{\mathrm{e}}$ & 25 & 76.0 & 76.0 & 72.0 \\
\hline Long-term follow-up ${ }^{71}$ & & T80/A5+Add-on ${ }^{\mathrm{e}}$ & $|8|$ & 46.4 & 59.7 & 70.7 \\
\hline Telmisartan plus & 34 & T40/A10 & 216 & 93.1 & 93.1 & 88.0 \\
\hline amlodipine study- & & T80/A 10 & 436 & 92.2 & 92.9 & 92.0 \\
\hline amlodipine 10 mg & & T80/A I0 (uptitrated) ${ }^{f}$ & 91 & 79.1 & 78.0 & 82.4 \\
\hline Long-term follow-up ${ }^{71}$ & & T40-80/A I0+Add-one & 92 & 76.1 & 79.3 & 75.0 \\
\hline \multirow[t]{2}{*}{ Trial no $1235.16^{89}$} & 56 & T40/A5 & 211 & 92.8 & 98.6 & 97.6 \\
\hline & & T80/A5 & 48 & 66.7 & 87.5 & 93.8 \\
\hline
\end{tabular}

Notes: aExcluded if SBP $\geq 180 \mathrm{mmHg}$ and/or DBP $\geq 120 \mathrm{mmHg}$; ${ }^{D} D B P$ control $=\mathrm{DBP}<90 \mathrm{mmHg}$; ${ }^{\mathrm{C} B B P}$ response $=\mathrm{DBP}<90 \mathrm{mmHg}$ or a DBP decrease of $\geq 10 \mathrm{mmHg}$; ${ }^{d} S B P$ response $=S B P<140 \mathrm{mmHg}$ or a SBP decrease of $\geq 15 \mathrm{mmHg}$; esubjects whose $\mathrm{BP}$ was not controlled were given additional antihypertensive medication; 'subjects in the T40/AIO arm whose BP was not controlled were uptitrated to T80/AI0.

Abbreviations: T, telmisartan; A, amlodipine; BP, blood pressure; DBP, mean sitting diastolic blood pressure; SBP, mean sitting systolic blood pressure. 


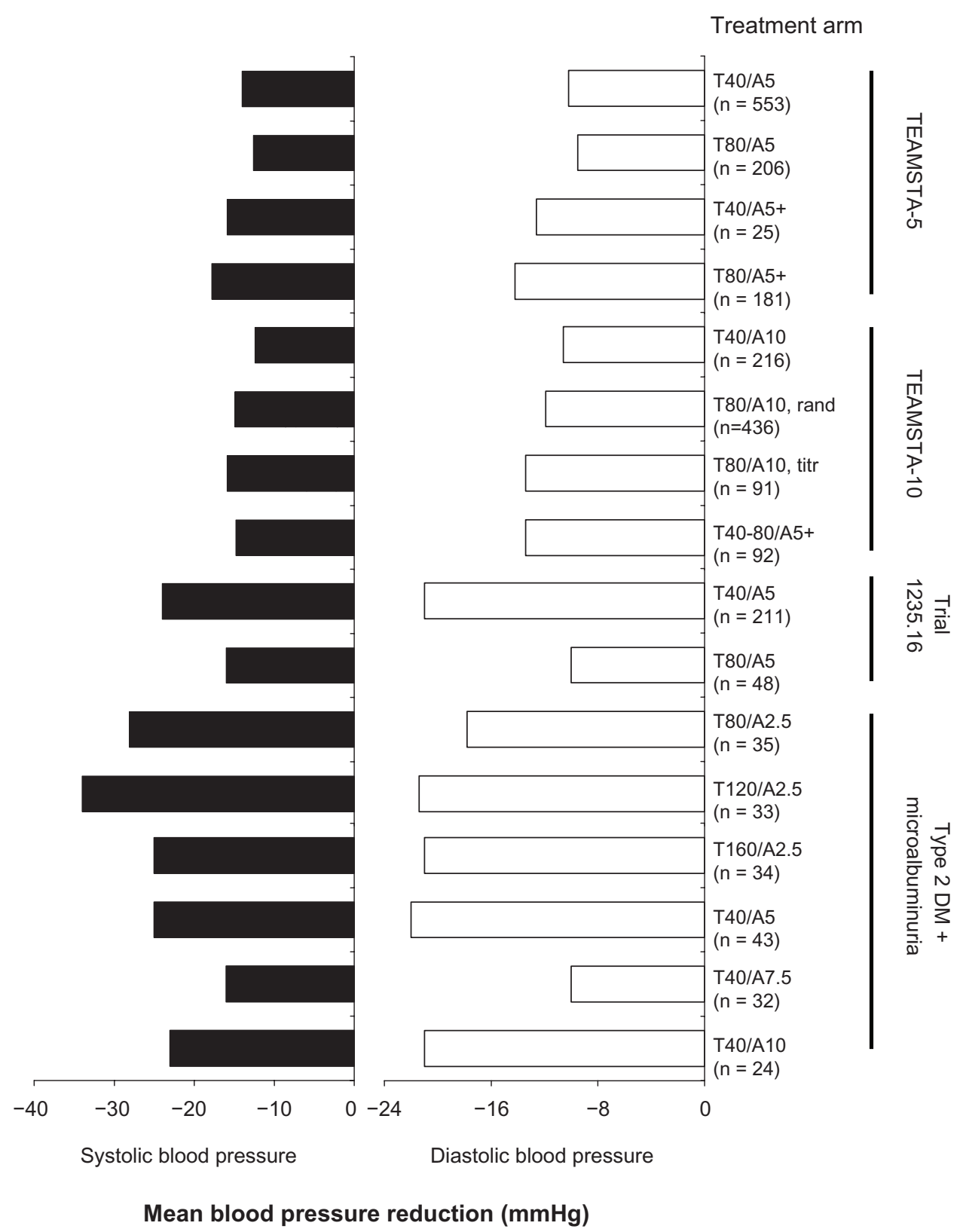

Figure 2 Mean blood pressure reduction by treatment arm from four long-term ( $>6$ months) clinical trials.

Abbreviations: rand, patients randomized to T80/A I0; T, telmisartan; A, amlodipine; TEAMSTA, TElmisartan plus AMlodipine Study-Amlodipine; titr, patients who were up-titrated to this dose, per the study protocol; DM, diabetes mellitus.

clear whether this greater drug exposure is also associated with a concurrent rise in $\mathrm{AE}$ incidence nor is it clear what effect coadministration with amlodipine may have on telmisartan pharmacokinetics (and vice versa) in women and certain minority populations.

\section{Additional long-term clinical trials for telmisartan/amlodipine combination therapy}

At the time of this publication, trials were underway or were of unclear status to further evaluate the long-term safety and efficacy of telmisartan/amlodipine therapy that may help expand the data available for underrepresented groups. Among the studies in progress are two actively recruiting trials and a third ongoing but not recruiting participants; these studies range from 26 weeks to 4 years. The trial of longest project duration, a phase IV study in which over 13,500 patients were randomized to evaluate the effect of low-dose telmisartan plus amlodipine versus amlodipine plus diuretics, aims to prospectively compare treatment regimens on hard clinical endpoints of stroke, MI, and death from CVD. ${ }^{87}$ This trial, from which some data have been 
published, did not utilize single pill telmisartan/amlodipine but rather used separate pills concurrently and hence was not included in prior sections of this review. However, 48-week and 96-week results showed that both arms were similar in their reduction of BP and control rates. ${ }^{87,88}$ Notably, AEs were mild to moderate, occurring in $<18 \%$ at 48 weeks; peripheral edema, which was one of the more common AEs, occurred infrequently over 96 weeks (24 patients in the diuretic arm and 17 patients in the telmisartan arm).

A second long-term study (ClinicalTrials.gov identifier NCT01353274) featuring the telmisartan/amlodipine combination pill is currently ongoing but no longer recruiting. In this study, an estimated 1200 patients will be followed for a year as part of a postmarketing surveillance endeavor designed to assess the long-term safety of the single pill telmisartan/amlodipine combination in Japanese subjects. A specific safety concern to be addressed by this study is the safety of the drug in patients with hepatic disorders, an issue being scrutinized due to the significant elevations of plasma telmisartan concentrations (3-4.5 fold) in these patients. Results of this study may become available as soon as mid-2013.

A 24-week efficacy trial in 2000 (projected) participants receiving telmisartan/amlodipine is underway with a primary endpoint of mean BP change (ClinicalTrials.gov identifier NCT01316419). In this study, additional endpoints include questionnaire-based quality of life assessment and additional risk factor changes during the course of the intervention. Results are expected in 2014.

Finally, there is a single-center 26-week study dubbed "TEAMSTAprotect" (ClinicalTrials.gov identifier NCT01180205) that was designed to evaluate and compare the effects of telmisartan/amlodipine versus olmesartan and HCTZ on flow-mediated dilation, a surrogate measure for endothelial dysfunction. The status of this trial, however, is unclear as its completion was estimated to occur in 2011.

Collectively, data from these additional trials will add to the breadth of public knowledge regarding the safety and efficacy of telmisartan/amlodipine combination therapy.

\section{Conclusion}

Available clinical trial data suggest that the telmisartan/ amlodipine combination pill is a safe efficacious option for the long-term treatment of hypertension. The complementary mechanisms of its components appear to enhance the effectiveness beyond that provided by each drug alone, including potential synergistic effects on endothelial function, while reducing some of the negative effects produced by amlodipine, such as peripheral edema. Furthermore, the potential effect(s) of telmisartan on the cardioprotective ACE2-ang (1-7)-Mas receptor axis may provide added benefits that have yet to be fully elucidated. Additional long-term data in hypertensive women and minorities may be warranted to further confirm the safety and efficacy of the telmisartan/ amlodipine combination pill in these populations.

\section{Acknowledgments}

The authors thank Dr Christine Billecke, $\mathrm{PhD}$, for her review and editorial suggestions for this manuscript.

\section{Disclosure}

The authors have nothing to disclose.

\section{References}

1. Mancia G, De Backer G, Dominiczak A, et al. 2007 Guidelines for the Management of Arterial Hypertension: The Task Force for the Management of Arterial Hypertension of the European Society of Hypertension (ESH) and of the European Society of Cardiology (ESC). J Hypertens. 2007;25(6):1105-1187.

2. Wolf-Maier K, Cooper RS, Banegas JR, et al. Hypertension prevalence and blood pressure levels in 6 European countries, Canada, and the United States. JAMA. 2003;289(18):2363-2369.

3. Egan BM, Zhao Y, Axon RN. US trends in prevalence, awareness, treatment, and control of hypertension, 1988-2008. JAMA. 2010; 303(20):2043-2050.

4. Heidenreich PA, Trogdon JG, Khavjou OA, et al. Forecasting the future of cardiovascular disease in the United States: a policy statement from the American Heart Association. Circulation. 2011;123(8):933-944.

5. Roger VL, Go AS, Lloyd-Jones DM, et al. Heart disease and stroke statistics - 2012 update: a report from the American Heart Association. Circulation. 2011;125(1):e2-e220.

6. Mosca L, Banka CL, Benjamin EJ, et al. Evidence-based guidelines for cardiovascular disease prevention in women: 2007 update. Circulation. 2007;115(11):1481-1501.

7. Melloni C, Berger JS, Wang TY, et al. Representation of women in randomized clinical trials of cardiovascular disease prevention. Circ Cardiovasc Qual Outcomes. 2010;3(2):135-142.

8. Lloyd-Jones DM, Evans JC, Levy D. Hypertension in adults across the age spectrum: current outcomes and control in the community. JAMA. 2005;294(4):466-472.

9. Mancia G, Grassi G. Systolic and diastolic blood pressure control in antihypertensive drug trials. J Hypertens. 2002;20(8):1461-1464.

10. Zanchetti A, Ruilope LM. Antihypertensive treatment in patients with type-2 diabetes mellitus: what guidance from recent controlled randomized trials? J Hypertens. 2002;20(11):2099-2110.

11. Copley JB, Rosario R. Hypertension: a review and rationale of treatment. Dis Mon. 2005;51(10-11):548-614.

12. Dahlof B, Sever PS, Poulter NR, et al. Prevention of cardiovascular events with an antihypertensive regimen of amlodipine adding perindopril as required versus atenolol adding bendroflumethiazide as required, in the Anglo-Scandinavian Cardiac Outcomes Trial-Blood Pressure Lowering Arm (ASCOT-BPLA): a multicentre randomised controlled trial. Lancet. 2005;366(9489):895-906.

13. Chobanian AV, Bakris GL, Black HR, et al. The Seventh Report of the Joint National Committee on Prevention, Detection, Evaluation, and Treatment of High Blood Pressure: the JNC 7 report. JAMA. 2003; 289(19):2560-2572.

14. Murphy J, Coster G. Issues in patient compliance. Drugs. 1997; 54(6):797-800. 
15. Gehi AK, Ali S, Na B, Whooley MA. Self-reported medication adherence and cardiovascular events in patients with stable coronary heart disease: the heart and soul study. Arch Intern Med. 2007;167(16):1798-1803.

16. Sokol MC, McGuigan KA, Verbrugge RR, Epstein RS. Impact of medication adherence on hospitalization risk and healthcare cost. Med Care. 2005;43(6):521-530.

17. Erdine S. Compliance with the treatment of hypertension: the potential of combination therapy. J Clin Hypertens (Greenwich). 2010; 12(1):40-46.

18. Claxton AJ, Cramer J, Pierce C. A systematic review of the associations between dose regimens and medication compliance. Clin Ther. 2001;23(8):1296-1310.

19. Domino FJ. Improving adherence to treatment for hypertension. $A m$ Fam Physician. 2005;71(11):2089-2090.

20. Bangalore S, Kamalakkannan G, Parkar S, Messerli FH. Fixed-dose combinations improve medication compliance: a meta-analysis. Am J Med. 2007;120(8):713-719.

21. Gupta AK, Arshad S, Poulter NR. Compliance, safety, and effectiveness of fixed-dose combinations of antihypertensive agents: a meta-analysis. Hypertension. 2010;55(2):399-407.

22. Dickson M, Plauschinat CA. Compliance with antihypertensive therapy in the elderly: a comparison of fixed-dose combination amlodipine/ benazepril versus component-based free-combination therapy. Am $J$ Cardiovasc Drugs. 2008;8(1):45-50.

23. Chapman RH, Benner JS, Petrilla AA, et al. Predictors of adherence with antihypertensive and lipid-lowering therapy. Arch Intern Med. 2005;165(10):1147-1152.

24. Hess G, Hill J, Lau H, Dastani H, Chaudhari P. Medication utilization patterns and hypertension-related expenditures among patients who were switched from fixed-dose to free-combination antihypertensive therapy. PT. 2008;33(11):652-666.

25. Wald DS, Law M, Morris JK, Bestwick JP, Wald NJ. Combination therapy versus monotherapy in reducing blood pressure: meta-analysis on 11,000 participants from 42 trials. Am J Med. 2009;122(3):290-300.

26. Quan A, Chavanu K, Merkel J. A review of the efficacy of fixed-dose combinations olmesartan medoxomil/hydrochlorothiazide and amlodipine besylate/benazepril in factorial design studies. Am J Cardiovasc Drugs. 2006;6(2):103-113.

27. McInnes GT. Antihypertensive drugs in combination: additive or greater than additive? J Hum Hypertens. 2007;21(12):914-916.

28. Yang W, Chang J, Kahler KH, et al. Evaluation of compliance and health care utilization in patients treated with single pill vs free combination antihypertensives. Curr Med Res Opin. 2010;26(9):2065-2076.

29. Burnier M, Brown RE, Ong SH, Keskinaslan A, Khan ZM. Issues in blood pressure control and the potential role of single-pill combination therapies. Int J Clin Pract. 2009;63(5):790-798.

30. Jamerson K, Weber MA, Bakris GL, et al. Benazepril plus amlodipine or hydrochlorothiazide for hypertension in high-risk patients. New Engl J Med. 2008;359(23):2417-2428.

31. Esposti LD, Di Martino M, Saragoni S, et al. Pharmacoeconomics of antihypertensive drug treatment: an analysis of how long patients remain on various antihypertensive therapies. J Clin Hypertens (Greenwich). 2004;6(2):76-84.

32. Corrao G, Zambon A, Parodi A, et al. Discontinuation of and changes in drug therapy for hypertension among newly-treated patients: a population-based study in Italy. J Hypertens. 2008;26(4): 819-824.

33. Bramlage P, Hasford J. Blood pressure reduction, persistence and costs in the evaluation of antihypertensive drug treatment - a review. Cardiovasc Diabetol. 2009;8:18

34. Wang W, Ma L, Zhang Y, Deng Q, Liu M, Liu L. The combination of amlodipine and angiotensin receptor blocker or diuretics in high-risk hypertensive patients: rationale, design and baseline characteristics. J Hum Hypertens. 2011;25(4):271-277.

35. Epstein BJ, Vogel K, Palmer BF. Dihydropyridine calcium channel antagonists in the management of hypertension. Drugs. 2007;67(9):1309-1327.
36. Messerli FH. Evolution of calcium antagonists: past, present, and future. Clin Cardiol. 2003;26(2 Suppl 2):II12-II16.

37. Burnier M. Telmisartan: a different angiotensin II receptor blocker protecting a different population? J Int Med Res. 2009;37(6):1662-1679.

38. Zheng Z, Lin S, Shi H. A systematic review and meta-analysis of telmisartan versus valsartan in the management of essential hypertension. J Clin Hypertens (Greenwich). 2010;12(6):414-421.

39. Siragy H. Angiotensin II receptor blockers: review of the binding characteristics. Am J Cardiol. 1999;84(10A):3S-8S.

40. Miura S, Karnik SS, Saku K. Review: angiotensin II type 1 receptor blockers: class effects versus molecular effects. J Renin Angiotensin Aldosterone Syst. 2011;12(1):1-7.

41. Singh BN. The mechanism of action of calcium antagonists relative to their clinical applications. Br J Clin Pharmacol. 1986;21 Suppl 2: 109S-121S.

42. Elliott WJ, Ram CV. Calcium channel blockers. J Clin Hypertens (Greenwich). 2011;13(9):687-689.

43. de Gasparo M, Catt KJ, Inagami T, Wright JW, Unger T. International union of pharmacology. XXIII. The angiotensin II receptors. Pharmacol Rev. 2000;52(3):415-472.

44. Verdecchia P, Angeli F, Mazzotta G, Gentile G, Reboldi G. The renin angiotensin system in the development of cardiovascular disease: role of aliskiren in risk reduction. Vasc Health Risk Manag. 2008;4(5):971-981.

45. Tuck ML. Angiotensin-receptor blocking agents and the peroxisome proliferator-activated receptor-gamma system. Curr Hypertens Rep. 2005;7(4):240-243.

46. Mori H, Okada Y, Arao T, Nishida K, Tanaka Y. Telmisartan at $80 \mathrm{mg} /$ day increases high-molecular-weight adiponectin levels and improves insulin resistance in diabetic patients. Adv Ther. 2012;29(7): 635-644.

47. Kakuta H, Sudoh K, Sasamata M, Yamagishi S. Telmisartan has the strongest binding affinity to angiotensin II type 1 receptor: comparison with other angiotensin II type 1 receptor blockers. Int J Clin Pharmacol Res. 2005;25(1):41-46.

48. Mallat SG. What is a preferred angiotensin II receptor blocker-based combination therapy for blood pressure control in hypertensive patients with diabetic and non-diabetic renal impairment? Cardiovasc Diabetol. 2012;11:32.

49. Meredith PA, Elliott HL. Clinical pharmacokinetics of amlodipine. Clin Pharmacokinet. 1992;22(1):22-31.

50. Stangier J, Su CA, Roth W. Pharmacokinetics of orally and intravenously administered telmisartan in healthy young and elderly volunteers and in hypertensive patients. J Int Med Res. 2000;28(4):149-167.

51. Stangier J, Schmid J, Turck D, et al. Absorption, metabolism, and excretion of intravenously and orally administered [14C] telmisartan in healthy volunteers. J Clin Pharmacol. 2000;40(12 Pt 1):1312-1322.

52. Atlas SA. The renin-angiotensin aldosterone system: pathophysiological role and pharmacologic inhibition. J Manag Care Pharm. 2007; 13(8 Suppl B):9-20.

53. TWYNSTA (telmisartan and amlodpine besylate) [package insert]. Ingelheim, Germany: Boehringer Ingelheim; 2011.

54. Noh YH, Lim HS, Kim MJ, et al. Pharmacokinetic interaction of telmisartan with s-amlodipine: an open-label, two-period crossover study in healthy Korean male volunteers. Clin Ther. 2012;34(7):1625-1635.

55. Stangier J, Su CA. Pharmacokinetics of repeated oral doses of amlodipine and amlodipine plus telmisartan in healthy volunteers. J Clin Pharmacol. 2000;40(12 Pt 1):1347-1354.

56. TEKAMLO (aliskiren hemifumarate and amlodipine besylate) [package insert]. East Hanover, NJ: Novartis Pharmaceuticals Corporation; 2010.

57. Cristovam PC, Arnoni CP, de Andrade MC, et al. ACE-dependent and chymase-dependent angiotensin II generation in normal and glucose-stimulated human mesangial cells. Exp Biol Med (Maywood). 2008;233(8):1035-1043.

58. Koka V, Wang W, Huang XR, Kim-Mitsuyama S, Truong LD, Lan HY. Advanced glycation end products activate a chymase-dependent angiotensin II-generating pathway in diabetic complications. Circulation. 2006;113(10):1353-1360. 
59. Lavrentyev EN, Estes AM, Malik KU. Mechanism of high glucose induced angiotensin II production in rat vascular smooth muscle cells. Circ Res. 2007;101(5):455-464.

60. Singh VP, Le B, Bhat VB, Baker KM, Kumar R. High-glucoseinduced regulation of intracellular ANG II synthesis and nuclear redistribution in cardiac myocytes. Am J Physiol Heart Circ Physiol. 2007;293(2):H939-H948.

61. Horita Y, Taura K, Taguchi T, Furusu A, Kohno S. Aldosterone breakthrough during therapy with angiotensin-converting enzyme inhibitors and angiotensin II receptor blockers in proteinuric patients with immunoglobulin A nephropathy. Nephrology (Carlton). 2006;11(5):462-466.

62. Athyros VG, Mikhailidis DP, Kakafika AI, Tziomalos K, Karagiannis A. Angiotensin II reactivation and aldosterone escape phenomena in renin-angiotensin-aldosterone system blockade: is oral renin inhibition the solution? Expert Opin Pharmacother. 2007;8(5): 529-535.

63. Greene LJ, Spadaro AC, Martins AR, Perussi De Jesus WD, Camargo AC. Brain endo-oligopeptidase B: a post-proline cleaving enzyme that inactivates angiotensin I and II. Hypertension. 1982;4(2):178-184.

64. Welches WR, Santos RA, Chappell MC, Brosnihan KB, Greene LJ, Ferrario CM. Evidence that prolyl endopeptidase participates in the processing of brain angiotensin. J Hypertens. 1991;9(7):631-638.

65. Yamamoto K, Chappell MC, Brosnihan KB, Ferrario CM. In vivo metabolism of angiotensin I by neutral endopeptidase (EC 3.4.24.11) in spontaneously hypertensive rats. Hypertension. 1992;19(6 Pt 2): 692-696.

66. Santos RA, Ferreira AJ, Simoes ESAC. Recent advances in the angiotensin-converting enzyme 2-angiotensin(1-7)-Mas axis. Exp Physiol. 2008;93(5):519-527.

67. Ferreira AJ, Murca TM, Fraga-Silva RA, Castro CH, Raizada MK, Santos RA. New cardiovascular and pulmonary therapeutic strategies based on the Angiotensin-converting enzyme 2/angiotensin-(1-7)/mas receptor axis. Int J Hypertens. 2012;2012:147825.

68. Iyer SN, Ferrario CM, Chappell MC. Angiotensin-(1-7) contributes to the antihypertensive effects of blockade of the renin-angiotensin system. Hypertension. 1998;31(1 Pt 2):356-361.

69. Davie AP, McMurray JJ. Effect of angiotensin-(1-7) and bradykinin in patients with heart failure treated with an ACE inhibitor. Hypertension. 1999;34(3):457-460.

70. Sukumaran V, Veeraveedu PT, Gurusamy N, et al. Telmisartan acts through the modulation of ACE-2/ANG 1-7/mas receptor in rats with dilated cardiomyopathy induced by experimental autoimmune myocarditis. Life Sci. 2012;90(7-8):289-300.

71. Neldam S, Edwards C, Lang M, Jones R. Long-term tolerability and efficacy of single-pill combinations of telmisartan $40-80 \mathrm{mg}$ plus amlodipine 5 or $10 \mathrm{mg}$ in patients whose blood pressure was not initially controlled by amlodipine 5-10 mg: Open-label, long-term follow-ups of the TEAMSTA-5 and TEAMSTA-10 studies. Curr Ther Res Clin Exp. 2012;73(1-2):65-84.

72. Fogari R, Derosa G, Zoppi A, et al. Effect of telmisartan-amlodipine combination at different doses on urinary albumin excretion in hypertensive diabetic patients with microalbuminuria. Am J Hypertens. 2007;20(4):417-422.

73. Littlejohn TW 3rd, Majul CR, Olvera R, et al. Telmisartan plus amlodipine in patients with moderate or severe hypertension: results from a subgroup analysis of a randomized, placebo-controlled, parallel-group, $4 \times 4$ factorial study. Postgrad Med. 2009;121(2):5-14.

Vascular Health and Risk Management

\section{Publish your work in this journal}

Vascular Health and Risk Management is an international, peerreviewed journal of therapeutics and risk management, focusing on concise rapid reporting of clinical studies on the processes involved in the maintenance of vascular health; the monitoring, prevention and treatment of vascular disease and its sequelae; and the involvement of Submit your manuscript here: http://www.dovepress.com/vascular-health-and-risk-management-journ
74. Fogari R, Zoppi A, Maffioli P, Lazzari P, Mugellini A, Derosa G. Effect of telmisartan addition to amlodipine on ankle edema development in treating hypertensive patients. Expert Opin Pharmacother. 2011;12(16): 2441-2448.

75. Fogari R, Zoppi A, Mugellini A, et al. Effect of aliskiren addition to amlodipine on ankle edema in hypertensive patients: a three-way crossover study. Expert Opin Pharmacother. 2011;12(9):1351-1358.

76. Sica DA. Rationale for fixed-dose combinations in the treatment of hypertension: the cycle repeats. Drugs. 2002;62(3):443-462.

77. TEKTURNA (aliskiren hemifumarate) [package insert]. East Hanover, NJ: Novartis Pharmaceuticals Corporation; 2007.

78. Neldam S, Lang M, Jones R. Telmisartan and amlodipine single-pill combinations vs amlodipine monotherapy for superior blood pressure lowering and improved tolerability in patients with uncontrolled hypertension: results of the TEAMSTA-5 study. J Clin Hypertens (Greenwich). 2011;13(7):459-466.

79. White WB, Littlejohn TW, Majul CR, et al. Effects of telmisartan and amlodipine in combination on ambulatory blood pressure in stages 1-2 hypertension. Blood Press Monit. 2010;15(4):205-212.

80. Littlejohn TW 3rd, Majul CR, Olvera R, et al. Results of treatment with telmisartan-amlodipine in hypertensive patients. J Clin Hypertens (Greenwich). 2009;11(4):207-213.

81. Sharma AM, Bakris G, Neutel JM, et al. Single-pill combination of telmisartan/amlodipine versus amlodipine monotherapy in diabetic hypertensive patients: an 8-week randomized, parallel-group, doubleblind trial. Clin Ther. 2012;34(3):537-551.

82. Bekki H, Yamamoto K, Sone M, et al. Efficacy of combination therapy with telmisartan plus amlodipine in patients with poorly controlled hypertension. Oxid Med Cell Longev. 2010;3(5):342-346.

83. Lacourciere Y, Krzesinski JM, White WB, Davidai G, Schumacher H. Sustained antihypertensive activity of telmisartan compared with valsartan. Blood Press Monit. 2004;9(4):203-210.

84. Littlejohn T, Mroczek W, Marbury T, VanderMaelen CP, Dubiel RF. A prospective, randomized, open-label trial comparing telmisartan $80 \mathrm{mg}$ with valsartan $80 \mathrm{mg}$ in patients with mild to moderate hypertension using ambulatory blood pressure monitoring. Can J Cardiol. 2000;16(9):1123-1132.

85. Nixon RM, Muller E, Lowy A, Falvey H. Valsartan vs other angiotensin II receptor blockers in the treatment of hypertension: a meta-analytical approach. Int J Clin Pract. 2009;63(5):766-775.

86. National Center for Health Statistics. Health, United States, 2011: With Special Feature on Socioeconomic Status and Health. W Hyattsville, $\mathrm{MD} ; 2012$.

87. Ma L, Wang W, Zhao Y, et al. Combination of amlodipine plus angiotensin receptor blocker or diuretics in high-risk hypertensive patients: a 96-week efficacy and safety study. Am J Cardiovasc Drugs. 2012;12(2):137-142.

88. Lu F, Zhao Y, Liu Z, Sun H, Sun S, Wang S. A 48-week study of amlodipine plus amiloride/hydrochlorothiazide vs amlodipine plus telmisartan in the treatment of hypertension. Int J Clin Pract. 2012;66(8): 792-799.

89. Boehringer Ingelheim Pharmaceuticals.An Open-label, Long-term Study of Telmisartan Plus Amlodipine Fixed-dose Combination. In ClinicalTrials.gov [website on the Internet]. Bethesda, MD: US National Library of Medicine; 2008 [updated May 18, 2012]. Available from: http://www.clinicaltrials.gov/ct2/show/NCT00618774?term=1235.16\& rank=1. NLM identifier: NCT00618774. Accessed September 24, 2012.

\section{Dovepress}

metabolic disorders, particularly diabetes. This journal is indexed on PubMed Central and MedLine. The manuscript management system is completely online and includes a very quick and fair peer-review system, which is all easy to use. Visit http://www.dovepress.com/ testimonials.php to read real quotes from published authors. 